\title{
Modified Railway Wheel Steels: Production and Evaluation of Mechanical Properties with Emphasis on Low-Cycle Fatigue Behavior
}

\author{
JOHAN AHLSTRÖM and BIRGER KARLSSON
}

DOI: $10.1007 / \mathrm{s} 11661-009-9969-\mathrm{z}$

(C) The Minerals, Metals \& Materials Society and ASM International 2009

\section{Erratum to: METALLURGICAL AND MATERIALS \\ TRANSACTIONS A, Vol. 40A, No. 7, July 2009, \\ pp. 1557-67}

DOI: $10.1007 / \mathrm{s} 11661-009-9846-9$

THERE were several typos inadvertently introduced to the author affiliations during production. The corrected affiliations are as follows:

JOHAN AHLSTRÖM, Associate Professor, and BIRGER KARLSSON, Professor, are with the Department of Materials and Manufacturing Technology, Chalmers University of Technology, Göteborg, Sweden. Contact e-mail: johan.ahlstrom@chalmers.se

JOHAN AHLSTRÖM, Associate Professor, and BIRGER KARLSSON, Professor, are with the Department of Materials and Manufacturing Technology, Chalmers University of Technology, Göteborg, Sweden. Contact e-mail: johan.ahlstrom@chalmers.se

The online version of the original article can be found under doi: 10.1007/s11661-009-9846-9.

Article published online June 30, 2009 